This is the author's final, peer-reviewed manuscript as accepted for publication. The publisher-formatted version may be available through the publisher's web site or your institution's library.

\title{
The political economy of growing a rural university in the United States using online education: an examination of incentives for educational imperialism and academic capitalism
}

Jeff Zacharakis, Mary Tolar, and Royce Ann Collins

\section{How to cite this manuscript}

If you make reference to this version of the manuscript, use the following information:

Zacharakis, J., Tolar, M., \& Collins, R. A. (2014). The political economy of growing a rural university in the United States using online education: An examination of incentives for educational imperialism and academic capitalism. Retrieved from http://krex.ksu.edu

\section{Published Version Information}

Citation: Zacharakis, J., Tolar, M., \& Collins, R. A. (2014). The political economy of growing a rural university in the USA using online education: An examination of incentives for educational imperialism and academic capitalism. International Journal of Lifelong Education, 33(4), 440-454.

Copyright: @ 2013 Taylor \& Francis

Digital Object Identifier (DOI): doi:10.1080/02601370.2013.857732

Publisher's Link:

http://www.tandfonline.com/doi/full/10.1080/02601370.2013.857732\#.U_SLLvRdXU8

This item was retrieved from the K-State Research Exchange (K-REx), the institutional repository of Kansas State University. K-REx is available at http://krex.ksu.edu 
The Political Economy of Growing a Rural University in the United States using Online Education:

An Examination of Incentives for Educational Imperialism and Academic Capitalism

Abstract

Rural colleges and universities in the USA struggle to recruit new students as their geographic region is depopulating and cost to attend classes on campus are increasing. Online education using the Internet is rapidly expanding as an effective growth strategy to reach new groups of students. In this paper we take the position that online education is a form of cultural imperialism and academic capitalism where curriculum developers and professors are motivated to enroll new students in order to maintain the credibility and strength of their programmes and host institutions. We argue that it is not our intent to be educational imperialists or capitalists. Rather these are unintended consequences of our actions. This argument is supported by political economy theory in that we are marketing a technical rational form of online education without awareness of its long-term cultural, economic, or political ramifications. Even though we pride ourselves on developing a high quality programme that in our eyes meet the needs of our students, understanding the political economy of online education is essential if our programme that has access to the global market is to go beyond the individual needs of students and address social, cultural and political needs. We conclude that one way out of this malaise is to understand our role as instructors and course designers 
as a first step toward understanding the intended and unintended consequences of online education.

Introduction

Research and analysis of educational imperialism from a Marxian, political economy perspective has been well developed over the last four decades (Carnoy, 1974; Gradstein, Justman \& Meier, 2005; Jarvis, 2008; McLaren, 2005; Youngman, 2000). A general criticism can be made that using educational imperialism is a dated Marxian concept, arguably archaic, which has lost traction today as globalization and international capitalism (Allan \& Turner, 2000; Bauman, 2000; Finger \& Asun, 2001) have become the dominant discourse in a world where multinational corporations have replaced nations as capitalistic and imperialistic political forces. Yet, we still see value in revisiting the notion of educational imperialism to better understand and deconstruct our role in developing online adult education programmes that sees no national or cultural boundaries. This concept of educational imperialism is then connected to academic capitalism (Rhoades \& Slaughter, 1997; Rhoades \& Slaughter, 2004; Slaughter \& Rhoades, 2004), open marketeering (Bagnall, 1999), and learning consumption (Jarvis, 2008; Usher, 2008). The issue of generating revenue to support our programmes goes straight to the heart of the imperialistic nature of expanding our markets and attracting new students. We believe that understanding this polemic will make us better at what we do-design, implement and deliver graduate courses to our students that will enable them to grow and achieve their personal goals. 
Our motivation to conduct this analysis evolved slowly. As faculty at a rural university we have witnessed over the last decade the continual struggle students face to overcome the barriers of money and time associated with long commutes to campus, only to find new opportunities at other universities offering online graduate programs. Our rural location was becoming a threat unless we could find another way to recruit students. When we first were asked by our college to develop an online masters programme in adult education we looked at it as a curriculum development and technological challenge. Our original strategy was merely to transfer our existing face-to-face curriculum to an online, asynchronous structure. During the planning and development of this programme we reviewed the websites of other online programmes and online course syllabi, focusing most on those programmes that we determined to be our stiffest competition. We also visited with peers and colleagues from other universities who either had developed an online graduate-degree programme, or were in the process of developing one. Without exception, we learned that the programmes we reviewed and the colleagues we visited did not consider complex issues related to cultural imperialism or academic capitalism. Though our colleagues did share how their online programme did increase enrolment and, therefore, revenues, no one made the claim that it was a more effective learning approach than the traditional classroom. Rather they looked upon their online programme as a necessary $21^{\text {st }}$ Century educational strategy to ensure the sustainability of their faculty and department.

Like our colleagues and competition, we also did not initially consider these more complex issues related to this analysis, and pursued this project as a way to 
grow our programme and recruit new students. Yet, in order for our programme to remain vibrant and effective we continue to examine our foundational beliefs from time to time. Through this self-examination, which is part of an ongoing autoethnographic study (Ellis, Adams \& Bochner, 2011) of our programme, we begin to explore the notions of educational imperialism, academic capitalism, and the political economy of education. Within the tradition of autoethnography this analysis is a political and socially conscious act that is grounded in our present and retrospective experience. This reflective path has changed the way we look at online education and as a result we now believe Carnoy's $(1972,1974)$ and Slaughter and Rhoades' (2004) theses are critical to understand and actualise if we are to grow and improve as educators and researchers. Our goal is to create awareness and hopefully an international dialogue on we as a profession might address these issues. The Problem of Online Education

Our analysis relies on Carnoy's seminal treatments of the corporatization of education in Schooling in a Corporate Society (1972) and Education as Cultural Imperialism (1974). We seek to understand our complicit participation and motives in furthering the expansion of our educational empire by exploring Sabates' (2003) philosophical analysis 'being without doing'. We argue that regardless of one's frame of mind, one does not relinquish his or her responsibility and culpability just because one claims ignorance, and therefore our analysis is an attempt to better understand unintended consequences. Possibly one thing we as online educators can do is to seek strategies that strengthen our students' social capital so they are better able to expand their networks and meet their personal and community goals. 
We are tenure-track professors of adult education and educational leadership at a rural-Midwestern research university in the USA with approximately 24,000 students. The closest urban communities to our campus are about 120 miles east and 120 miles south. Though our reputation in this region and throughout the country is strong, our students have many choices including more affordable state and public colleges and universities, as well as more prestigious private and public universities. Yet as is true with all university faculty we seek to recruit the best students and fill our classes. If we fail at this task and our enrolments decline we face contraction and thereby become institutionally weaker. We argue that higher education is a business and with declining state and federal public monies our business acumen must improve. These financial incentives, as with most rural universities throughout the world, are accentuated and compounded as our traditional rural geographic areas depopulate and transportation costs for students coming to campus increase. The opportunities for residential experiences in higher education in pursuit of intellectual and social growth are balanced by a curriculum that must emphasise the practical return on investment expected from an undergraduate or graduate diploma.

Our analysis examines economic incentives for universities to expand into higher education's global and domestic market through mediated learning and nontraditional academies that meet virtually, or at most on occasional weekends. Using our adult education graduate programme to illustrate a growth strategy that is rapidly being adopted by many rural and urban universities in Western, developed countries, we recognise the economic incentives to maximise tuition dollars related 
to full enrolment. Several layers below these motivating incentives are the mechanics of the political economy of educational imperialism and academic capitalism that thirst to continually find new students. With mediated learning in which physical capital is the mysterious structure of the Internet rather than bricks and mortar, these growth strategies typically do not consider political, economic, cultural, and social ramifications that result when curricula and educational strategies are developed in one culture and transferred to other cultures. Nor do these growth strategies consider underprivileged students' financial barriers. With little scholarship monies available, students either have the financial resources to pay for tuition and fees or they apply for student loans and grants. Yet the Internet allows our programme, and many programmes like ours, to access potential students from across the country and the world who already have the financial resources to strengthen their educational skills and résumés, therefore helping them retain their competitive advantage in a global capitalist market. Hence the argument might be made that programmes such as ours reproduce class structures. Though this analysis may seem crass and naïve, we admit that we are fully eognizant of our role in this imperialistic expansion and are willing partners in this growth strategy as part of our responsibility to our home institution and our need for job security. We are entrepreneurs, and we like the challenge of developing new programmes for new clients (often mistakenly referred to as merely students) whom we want to serve. In order to be successful in this mission, we strive to align quality with quantity not only because we are agents representing our university but also because we believe our product (student learning which leads to a diploma) 
has value. This pursuit of quality mollifies our ineptitude or impotence to serve disadvantaged students and their communities who cannot afford to enroll in our classes but are deserving and intellectually capable.

Educational Imperialism and Academic Capitalism

In Education as Cultural Imperialism, Carnoy (1974, p. 1) lays out the foundation of what seems to be a logical argument by identifying the obvious, 'formal education is an important institution for transmitting knowledge and culture from generation to generation....and the production of new knowledge'. He continues to describe how educators 'stress the enlightening function of the school: they claim that formal schooling is an important component of a lifelong process of education' (1974, p. 1). Then, just as we start to believe the pureness and fidelity of our vocation, Carnoy challenges us with the naked realization that 'Western schooling in the Third World and in the industrialised countries themselves' is not the liberating force we envision but is a part of a complex web of 'imperialist domination' (1974, p. 3). Specifically he argues, 'schooling was organised to develop and maintain, in the imperial countries, an inherently inequiteable and unjust organisation of production and political power' (1974, p. 3). The notion of production and political power is hard for us to fully comprehend as we develop programmes that focus on the technical-functional aspects of education and leadership. From our vantage point at a rural university within a dense sea of wheat and prairies we shy away from political or economic ramifications and strive to be exceptional teachers and advisors for students. This self-reflective analysis has forced us to ask if it is enough to be technically exceptional at teaching and advising. 
Through this self-reflection we find our online programme aligning with Bagnall's

(1999) description of open marketeering as a postmodern response to Usher's (2008) consumer learning.

Carnoy (1974, p. 4) accurately describes modern higher education as the engine in a development paradigm; 'traditional theory of schooling is based on the widely held view that Western education brings people out of their ignorance' and that 'schooling contributes to individual and collective development when it contributes to individual and collective increases in material output' (1974, p. 5). Based on what our students tell us they want from a college degree, there must be a return on their investment in order to attract quality students, collect their tuition, and justify the public tax monies our institution receives. Our students are expected to pay (often by taking out loans) for tuition and books. If their education is not fungible to better jobs and status, there is little incentive to enroll in our programme. We cannot afford to engage Carnoy in this critical analysis and reflection only to come to an agreement on the folly of our vocation. Still Carnoy $(1974$, p. 7) is not done as he reminds us that a student only 'has access to a larger slice of the economic and social pie, provided that everybody else has not gone to school with him [or her]'. In other words, for schooling to be attractive to the student and effective in maintaining social structures, it must serve as a filter that selects and rejects students for various reasons. Case in point, our programme has a limited number of partial scholarship awards (though loans are available to all full-time graduate students), there is not nearly enough to support those students most in need. We also follow university guidelines that stipulate minimum grade-point averages and 
educational requirements for all applicants. Hence the filter we use is twofold:

Students must be able to pay the tuition and fees and they must have been successful in their undergraduate education. This filter, though not unique to our university, rewards those who are already academically and economically successful.

If we agree that schooling, or more specifically the schooling we provide, is an economic engine available to everyone and is essential to developing a learning society, then we should take Carnoy $(1974$, p. 13) to task in his assertion which is based on economic data that 'the efficient schooling system in this type of growthmaximising development model clearly does not concern itself operationally with equalising economic opportunity'. We don't; instead, we find ourselves in agreement. In our study of educational imperialism and educational capitalism, we ask ourselves if we are guilty of his accusation that 'schools must help convince or reinforce children [and adults] in believing that the system is basically sound and the role they are allocated is the proper one for them to play' (1974, p. 13). This is a sales and marketing issue as we seek to promote our programme and recruit the best students who have the ability through the Internet to shop for programs that best fit their individual needs (Bagnall, 1999) and where marketing and consumption shapes their identity (Usher, 2008). Forty years after Carnoy published this book in today's declining or at best stagnant job market, we promise (in reality we don't promise, we only suggest the possibility of) more opportunity once the diploma is issued. We gain support from the National Centre of Educational Statistics that reports annually that those with higher levels of education generally 
have higher levels of median salary in the U.S. (Snyder \& Dillow, 2011). As educators, are we deluding ourselves as well as our students by suggesting that students can rise in this illusionary capitalist hierarchy by having more education and diplomas alone? As we reflect, though we may believe otherwise, our programme is not equalising economic opportunity through education. Rather it has self-serving motives and imperial aspirations as we seek to colonise (recruit, enroll, and graduate) more students, and enrich our faculty, department, and university through academic capitalism.

Faculty and department chairs are keenly aware that certain activities are necessary to increase revenue, either through enrolment, consulting, or research. Therefore the successful department is composed of entrepreneurs who are able to compete with other departments and universities for new students and new research dollars. Altbach, Reisberg, and Rumbley (2010, p. 31) in a report to UNESCO make the argument that 'despite higher education's greater inclusiveness, the privileged classes have retained their relative advantage in nearly all nations'. This analysis leads us back to Carnoy's (1974) assertion thirty-five years earlier that students will reap economic benefits from more education if and only if not everyone has the same access to this education. With the expanded market and access through online education, we at best devalue the product and reduce the potential return on investment students might experience.

Social Capital and Reproduction

Yet, the benefits of higher education go far beyond the mere acquisition of knowledge. Our graduates become enfranchised into our university networks and 
the professional networks in our discipline. This type of social capital (Granovetter, 1973) that creates bridging and bonding ties are intended to enhance our students' political, physical, financial, and cultural capital. This social capital has value not only to the student but also the institution through membership in alumni organisations that hopefully support the institution once our graduates achieve financial success. With todays all but open-access to higher education where everyone can find a college or university that will accept them, can web-based instruction supply the same quality of bridges and bonds inherent within the social capital they might have gained if they had attended classes on campus? Is this possible in a class of 25 students where no one lives in the same community, never meet each other face-to-face, and typically reside in 10-15 different states and 2-3 different countries? Will they develop friendships that create new bridges essential for their personal success? Will they develop ties with the university from which they can attribute their success? Are we expanding and marketing education to a level where everyone who has the financial capacity gains access regardless of qualifications, thereby weakening potential social networks of bonds and bridges, and ultimately as Carnoy argues negates its value? Or are we reproducing and strengthening the status quo by increasing the social capital of only those who pass through the filter that determines who can enroll?

Though the social capital aspect of higher education may be diminished as access increases and web-based technologies become more prevalent, is Carnoy's (1974, p. 43) thesis that we are using schooling to bring 'people into the capitalist culture, make them function more rationally, and make them more efficient 
producers...' still valid? Schooling's function, if Carnoy $(1974$, p. 50) is correct in his analysis, is for 'education as a whole to be more 'relevant' to the development process, which means it should be less oriented toward traditional disciplines such as law and the humanities, and have a more science-oriented curriculum'. The solution therefore to this 'educational crisis is the introduction of education technology. The stated purpose of educational television, radio, and computerised instruction [and now web-based instruction] is to substitute relatively 'cheap' forms of instruction...' for more expensive forms of instruction where students come to the university and work side-by-side with professors and researchers, a dying paradigm that is more elitist and limits the world's population who seek postsecondary education (1974, p. 51). In spite of limitations described above, we see the strengthening of student social capital within this online education's hegemonic structure to have at least some potential for transformative possibilities as students meet and interact with each other and share their different values and beliefs. Colonisation and Imperial Motives

Fast forward to the present with increasing pressure on colleges and universities to place more monetary and intellectual value into degree programmes that create immediate job opportunities for their graduates (Carnevale, Strohl, \& Melton, 2011), and multi-national agreements between European countries that reflect the competitive globalised labor market (Bologna Process, 2009). Our world today sees lifelong learning as 'obtaining qualifications, extending knowledge and understanding, gaining new skills and competences or enriching personal growth' (2009, p. 3). Its implementation 'requires strong partnerships between public 
authorities, higher education institutions, students, employers and employees' (2009, p. 3). Will this market-driven education result in an anti-intellectual technical-instrumental educational format at the expense of culturally and foundationally rich curricula that ask why things are the way they are and what the future will look like?

Whereas the original framework of imperialism focuses on the relationship between the dominant group (the metropole) and the periphery as observed in relations between Western nations and their colonies (Hobson, 1902), in today's world national boundaries are blurred and replaced by organisational structures. Even though most dominant organisations reside in Western developed countries and benefit from their location, they still put their organisational identity first and national identity second. Jarvis (2008, p. 19) argues that the 'West still exports their culture and commodities thought a different mechanism', and that corporations in this modern manifestation of imperialism 'control the means of spreading knowledge about their products as they seek to convince the public to purchase what they produce' (p. 20). Hence universities such as Harvard or Oxford, or companies such as Apple or British Petroleum, see themselves as both Western and international organisations, unlike state or regional universities such as ours which are primarily grounded in their geography. However in the field of adult education and educational leadership, our department and university has a strong reputation and necessary technical support to grow beyond its traditional geographical boundaries. As our programme graduates more students, they become ambassadors who in all likelihood become our disciples spreading our gospel across the country 
and the globe. Couple this public relations team with the reputation that American universities enjoy, and our graduate programme becomes a university of choice for many potential students. This market potential is in large part due to our advantage in educational technology where we have the resources to institute web-based enterprises and our capacity to generate awareness through marketing.

Citing Mannoni (1950), Carnoy (1974, p. 59) identifies the strong 'universal psychological drives to dominate others or be dominated'. Mannoni's thesis is structured around the previous condition between the coloniser and the colonised that shapes their relationship. This condition is permanent and can only be changed through psychotherapy. Hence it might be argued that this dependent relationship is both conscious and unconscious, and to be engaged as either the coloniser or the colonised does not require overt actions or activities. Using Memmi (1965) and Fanon (1968) to understand this relationship, Carnoy (1974, pp. 61-62) takes this argument one step further and suggests there is a predisposition toward being either the coloniser or colonised. Memmi refers to the situation that the colonised face as 'double alienation,' where the first alienation is having one's culture destroyed or usurped and the second alienation is the 'distorted image' of the dominant culture being imported through elements such as books, movies and curricula (Carnoy 1974, p. 63). Therefore the legitimacy of this relation emerges from a complex set of economic, social, political and psychological elements, where education becomes an effective instrument to maintain Western hegemony.

As with most university faculty faced with the same challenges, when we started this analysis we did not see ourselves as imperialists who are out to extract 
resources and dominate other cultures or people, or as capitalists whose goal is to become successful entrepreneurs amassing a large market share. Our goal was merely to develop the best possible online education programme in adult education and educational leadership that is sustainable. To justify our curriculum, we built it around the Commission of Professors of Adult Education (2008) standards for adult education graduate programmes in the USA. Our approach was and is based on best practises. Our motives though are in part self-serving as we strive to develop a strong sustainable programme with growth potential, which is necessary for our job security. We are also professionals who take great pride in our craft and are not willing to sacrifice quality in order to achieve quantity. In fact we have developed safeguards through evaluation, assessment and double-loop learning so we can continuously improve our teaching, curricula, and overall product. Yet according to Carnoy we are imperialists because of the need and desire to grow our programme by increasing the number of students, and encouraging our graduates to help us market our programme beyond our traditional territorial borders. And within the framework of Rhoades and Slaughter $(1997,2004)$ we have no choice but to find new revenue streams if we want to have a sustainable programme. We now find ourselves engaged in postmodern capitalism as we pursue market diversification offering a curriculum that caters to individual instrumental learning and is attractive to the broadest base of consumers.

This being said, we need to explore philosophical concepts of causality, intent and motive. Sabates (2003) in his article 'Being Without Doing' explores the concept of epiphenomena, those conscious or unconscious activities that occur without 
causality, such as intentions, memories, feelings and emotions. The concepts of causality and epiphenomenalism are important if we are to accept Carnoy's implicit argument that our programme is a form of educational imperialism or Slaughter and Rhoades' analysis that we are subservient to the capitalist movement in higher education, even if unintended or unconscious.

Faced with the institutional need to grow, we probably don't have a choice to abandon this project in hopes of maintaining our ethical purity just because we now see that we are part and parcel to educational imperialism or academic capitalism. Changing course is not an option. This is where Hobson (1902) is correct in his assessment of European imperialism in Africa. Given our two choices, denial or acceptance of our imperial motives, we accept that we share the same thirst for challenge and adventure as our forefathers in building a new education programme, even though from Carnoy's (1974) perspective it depends upon taxing (e.g. tuition and fees) the subjects in our expanding geographic empire.

If satisfied with the product (our university's degree and their learning) these students then market our programme to others who also may be interested in enrolling. The cause and effect chain is quite obvious if growth, job security and believing that our product has value are the stimuli. If our unconscious motive or desire is to inculcate students with our values and beliefs in order to subjugate them and strengthen our financial and cultural capital, then the cause and effect chain becomes tenuous if not imaginary. The social capital that we seek to formulate among our students is therefore designed to strengthen our institution and its cultural capital necessary to expand into new markets and recruit new customers. 
We need our graduates to feel a part of our university community so they can and will market our programme to their friends and peers. We need them to believe and experience that a diploma from out programme will result in greater return on investment than our competition.

The Political Economy of Online Expansion

Using Marx's correspondence principle, Bowles and Gintis (1976, p. 11) argue that educational systems serve to reproduce social relations of production and corresponding forms of consciousness and socio-economic hierarchical structures. They accurately note that teachers do not do this through 'conscious intentions' but through social and cultural relationships in the workplace and schools-the unconscious. One result is what they refer to as the 'docile worker' (1976, p. 12), which obviously includes teachers, administrators and school board members. Faculty tenure at the university level (and this same argument can be applied to P-12 public school teachers) is but one powerful mechanism that spawns conformity, a symptom of docile acceptance of the status quo (Leverenz, 2000). In order to earn tenure, one unwritten rule is how does this teacher or faculty member fit with the department's faculty and culture. Moreover, tenured faculty typically vote on the qualifications of tenure candidates within their department, all but ensuring generational transfer of departmental and school culture, and therefore the reproduction of the status quo. On the other hand, we must also consider the docile student, teacher, their families, and community. In fact, the educational system is so engrained that except for some lonely intellectual voices in universities who really have little power, systemically the system is not questioned or 
challenged. When change does occur as a result of critical examination and analyses, it only occurs on the margins.

Gramsci (1988) identifies this as hegemony of the state, but in fact it might be more accurately identified as hegemony of the culture. We cease to ask the question, or even to question the question, of why things are as they are and why we do what we do. Bourdieu $(1977,1986)$ articulates how the dominant group or groups control the economic, social and political resources through their embedded culture in schools. The structure of our educational institutions favors those who already possess cultural capital (such as tenured faculty and students who can afford to enroll), which fits the criteria of the dominant hegemony. The schools, he argues, take the cultural capital of the dominant group as the natural and only proper sort of capital, and treat all children and adults as if they have equal access. Hence the cultural capital that schools take for granted acts as an effective filter in the reproductive processes of a hierarchical society. As if stuck in Plato's Cave (Plato, 2000), if we were released and able to see another world in which we have no prior experience, it will, at first, be beyond our understanding. Upon returning to the cave and sharing our experience, will we risk persecution for challenging the status quo and accepted wisdom? Therefore, each of us faces the dilemma of being the docile worker or the radical voice of the one who ventured outside the cave. Without middle ground both sharp and distinct horns represent impotent positions that we really don't covet.

In our pursuit of the finest online programme grounded in best practises, we become technocrats. We fail to see outside our cave as we develop curriculum based 
only on what we know. In so doing, we fall prey to unwittingly building a technocratic school, as described by Bowles and Gintis (1976, p. 47), in its overemphasis on cognitive skills as the basic requirement of job adequacy...[which] cannot even entertain the idea that the correspondence between the social relations of production and the social relation of education - the essential mechanism of the integrative function of schooling—-might preclude an egalitarian or truly humanistic education. If we become too ideological, or if we challenge their innate assumptions will our students hear us and enter into a dialogue to fully deconstruct the question? We have found graduate students reluctant to challenge bias and cultural beliefs. Instead of engaging, students view the instructor as having a political agenda when complex socioeconomic or cultural issues are introduced. Studies have documented false student perceptions of political bias of instructors based on their own beliefs and not the professor's (Anderson \& Kanner, 2011; Linvill, 2011). Anecdotally we have all witnessed such student perceptions and simply avoided the complex underlying issues by approaching the problem as merely miscommunication.

The United State's educational structure seeks stability through rationality, a rationality that is oblivious to anything other than the status quo. Ergo, if our programmes are to succeed they must first and foremost transfer skills through best practises within the dominant discourse. Granted we can introduce students to Marx, Gramsci and Carnoy, but only within an historical, apolitical context. To revere all three or even one is to take a position which is contra-positional to the dominant 
discourse. Thus, we become guilty of doing without doing in the epiphenomenal sense (Sabates, 2004).

The Deterritorialised Student

We understand that Marx, Gramsci, and even Carnoy are not postmodern and see the world in a grand solid structure where a unified blueprint is still the goal. Even though their important contributions to our thinking cannot be underestimated, we live in a postmodern society that is complex, rapidly changing and liquid. This underlying issue and our concern with educational imperialism stems from our relationship with ethics, morality, and society. Bauman (2000) helps us to understand the difficulty we face in this relationship as he tries to connect politics, community and togetherness with ethics and morality. Bauman points out that as we try to legislate moral and ethical behaviour we are in fact trying to mitigate uncertainty while we grapple with good and evil (educational imperialism is of course evil). The solid is modernity where the ideal is eliminating ambiguity and ambivalence. Alternatively, the liquid, the postmodern world in which we live, presents three challenges to the solid: the risks that we face every day in society; the deterritorialising of the nation-state; and fluid state of global capital that is not tied to place. Possibly if we look at these three challenges in reverse order a better understanding of their inter-relatedness can be developed. Fluid capital (financial as well as cultural) can be rapidly moved to anywhere in the world where the highest returns can be achieved, in essence attacking the foundation of nation-states and thereby creating a more complex, less secure society with higher risks for individuals. The result is a form of social disintegration, resulting in increased 
individual freedoms and privatization. All of this leads to a form of deterritorialising and disengagement from historical structures such as community, culture, geography, and norms. Not only is the individual more responsible for their decisions, he or she is more malleable. This deterritorialised individual with the appropriate academic credentials and financial means is the ideal candidate for online academic programmes.

Though this simplification of Bauman's (2000) thesis does not do it justice, it does shed light on how Hobson (1902) and Carnoy's (1974) view of imperialism needs to be reinterpreted in order to understand today's reality of academic capitalism (Slaughter \& Rhoades, 2004), open marketeering (Bagnall, 1999), and consumptive learning (Jarvis, 2008; Usher 2008). Organisations have replaced nation-states, and their markets know no geographic boundaries. The result is that weak global (including virtual) relations have replaced strong communal relations, and a culture of individualism has replaced collectivism and tribalism. For our university and online programme to grow our market is no the longer surrounding communities, but individuals who are dispersed and disconnected except for a common desire to earn a degree in adult education. Relations now last only as long as they are useful and satisfying, or as long as students remain in our programme (this same argument can be made for residential programmes but we believe that bonds grow stronger when there is more personal contact when compared to virtual learning). How they use the tools and skills they learn in our programme for the most part go unseen by professors in this highly mobile and disconnected world, except in those rare instances when we get an email or postcard from a student that 
reconnects with us for the briefest of moments. The seeds of our labor are planted somewhat haphazardly without us seeing if fruit is ever harvested.

Technical Instrumental Learning

As a result, our curricula as Bowles and Gintis (1976), Carnoy (1983), and Bagnall (1999) argue, are more technical and instrumental oriented (information that leads to practical application), and less grounded in philosophy, sociology and culture. Education is not a process toward understanding or enlightenment; it is a means to an end that typically is a higher paying job and greater status. Even when philosophical and historical components are incorporated, students push back with questions as to why this is important. Foundational knowledge has become something 'found' at another time, if necessary, and not worthy knowledge to possess. Skills and technology curricula are safer as most are derived from empirical research, and appear to be apolitical and pasteurised from all culturally sensitive bacterium. Our moral and ethical issues, as Bauman (2000) argues, are diminished and set aside as we respond to our disconnected students in a liquid modern society where our mantra is to serve our students (but not the communities and cultures in which they live) and build our programme and teaching around best practises (but not around unintended outcomes). How do we find the balance between rationalised specialty and special interest education? We respond to individual student needs and requests through our assessments and evaluations that are programmed into the double-loop learning we use. The educational culture seems to have conditioned students to only request new material that relates to skills and technology that are fungible and have a tangible return on investment. 
Employability influences students to evaluate higher education programmes that first and foremost will help them achieve their personal goals where allegiance and reference is not to community or culture but only ones self.

Though we have political beliefs and values in our personal lives, we designed our curricula and programme to attract emancipated autonomous individuals who may or may not share our beliefs. We control the political content so that every student can safely share their beliefs and will hopefully listen to students who have opposing values and beliefs. In doing so, we create an environment where we don't normally express our personal biases and beliefs in order to be unencumbered and unbiased facilitators. Yet each of us has personally experienced the wrath of students when through the curriculum we challenge their beliefs and values, and try to contextualise their political existence. When discussing feminist pedagogy, male students generally enter the discussion with a strong bias against it even though they do not have a grasp of the subject. Though the instructor takes careful steps to not appear in support of any specific pedagogy, throughout the online sessions students are antagonistic and disregard the content as well as the female instructor (Enns \& Sinacore, 2005). We police ourselves to the point of being politically correct in all discussions, thus succumbing to the hegemony of dominant culture. Our programme is political in that it strengthens the global status quo and reproduces its culture (Bourdieu, 1977, 1986) through education in the liquid modern (Bauman, 2000) by focusing curriculum on the technical-rational rather than the social-political.

Political Economy of our Programme 
Youngman's (2000) thesis on the political economy of adult education brings us back to Carnoy's (1974) solid modern analysis of educational imperialism. Youngman captures this connection between the solid and liquid modern forms of educational imperialism from his vantage point in Botswana, a former British colony. He describes how UNESCO sees the potential of education to eradicate disease, increase agricultural production and strengthen democratic institutions through literacy and lifelong learning. As a tool for development, 'it is expected that in such ways adult educational programmes can contribute to the economic, political and social dimensions of development' (Youngman, 2000, p. 2). However Youngman is not a believer and asks, 'Does adult education in fact help to create more secure livelihoods? Does it really empower marginalised groups in society? Does it genuinely contribute to democratisation?' (2000, p. 2). Arguing from a nondogmatic interpretation of Marx and Engels, Youngman (2000, p. 2) illustrates how 'the current stage of capitalist development is characterised by the dominance of transnational corporations, the microelectronics technological revolution, expanded consumerism, ecological crisis and the intensified (though uneven) incorporation of post-colonial societies into the global capitalist economy'. Our online programme is only possible because of the technological revolution and the opportunity for the global reach it creates. What we have created reflects an environment of consumerism (students decide where to study and corporations decide where to invest research funds) that is becoming the norm in higher education as public funds decrease and traditional markets shrink (Jarvis 2008, Usher 2008). In an era of fluid capital where the consumer can purchase what is wanted from whoever is 
able to offer it, our online students are becoming one of our major sources of income. We now treat them as customers who come to us for a safe (in that we don't challenge their assumptions) and relieable (the degree they earn from us has value) programme. In return we consciously or subconsciously provide the same basic curriculum regardless of their culture, economic status, or ethnicity. We are not in a position to empower marginalised groups, but the unintended outcome is the incorporation of dispersed individuals into the global capitalist economy. Conclusion

Carnoy's (1974) concept of educational imperialism moved us to engage in this self-examination of our online graduate program in adult education. Altbach (2002: 13) argues that higher education is now an internationally traded commodity that can be 'purchased by a consumer in order to build a 'skill set' to be used in the marketplace' rather than as 'a set of skills, attitudes and values required for citizenship and effective participation in modern society'. The unintended outcome of participating in the global capitalist economy is not discussed between our faculty, with our students, and prior this examination seldom considered in our thoughts and intentions. Through our analysis of education in today's online environment where the goal is to recruit new students and grow our programme beyond its traditional geographic boundaries, we conclude that what we have been doing is a form of educational imperialism and academic capitalism in our liquid modern world. The results are not the colonising of nation-states but the capturing of non-territorial individuals as new clients. 
For rural universities and colleges the opportunities that web-based education present cannot be overlooked. Whereas ten years ago our student base was limited by the geographic boundaries of our region, we now have access to the world though our curriculum remains firmly grounded in our historic culture and values. We, like many multinational corporations, see our future growth not in nation-states but in transnational markets. Our students not only receive quality teaching and advising, they are also subconsciously imbued with our values and culture that rewards individualism over community, family and indigenous culture. By exploring the choice to accept or deny our imperial and capitalist motives, this paper attempts to better understand our conscious and subconscious desires for growth and conquest as an essential step toward responding to the ethical question of educational imperialism. This self-reflection on educational imperialism, academic capitalism, motives, and political economy is not easy, nor does it ensure that we can find a way out of this malaise. It is, though, a first step to understanding how online education and the promise of new markets and programme sustainability is more complex than merely writing and teaching virtual courses on the Internet.

References

Allan, K. \& Turner, J.H. (2000), A formalization of postmodern theory.' Sociological Perspectives, 43(3), 363-385.

Altbach, P.G. (2002, April). Farewell to the common good: Knowledge and education as international commodities. International Educator, 11(4), 12-17.

Albach, P.G., Reisberg, L. \& Rumbley, L.E. (2010, March/April). A global academic 
revolution. Change Magazine, 30-39. Retrieved from:

http://www.changemag.org/Archives/Back\%20Issues/March-

April\%202010/tracking-global-full.html

Anderson, K., \& Kanner, M. (2011), Inventing a gay agenda: students' perceptions of lesbian and gay professors. Journal of Applied Social Psychology, 41(6), 15381564.

Bagnall, R.G. (1999). Discovering a postmodern agenda in adult education: Building a postmodern agenda in adult education. New York: Peter Lang.

Bagnall, R.G. (2000). Lifelong learning the limitations of economic determinism. International Journal of Lifelong Education, 19(1), 20-35.

Bauman, Z. (2000), Liquid modernity. Cambridge, UK: Polity.

Bologna Process, 2020 (2009), Communiqué of the conference of European ministers responsible for higher education, Leuven and Louvain-la-Neuve, 28-29 April 2009. European Commission on Higher Education \& Training.

Bourdieu, P. (1977), Outline of a theory of practise. Cambridge, U.K.: Cambridge University Press.

Bourdieu, P. (1986), The forms of capital. This is a chapter. J. Richardson (Ed), Handbook of theory and research for the sociology of education (pp. 241-258). New York: Greenwood.

Bowles, S. \& Gintis, H. (1976), Schooling in capitalist America: Educational reform and the contradictions of economic life. New York: Basic Books.

Carnevale, A.P., Strohl, J., \& Melton, M. (2011), What's its worth: The economic 
value of college majors. Washington D.C.: Georgetown University Centre on Education and the Workforce.

Carnoy, M. (1972), Schooling in corporate society: The political economy of education in America, New York: David McKay.

Carnoy, M. (1974), Education as cultural imperialism. New York: David McKay. Carnoy, M. (1983). Education, democracy, social conflict. Harvard Educational Review, 53(4), 398-402.

Commission of Professors of Adult Education (2008), Standards for graduate programmes in adult education. Washington, D.C.: American Association for Adult and Continuing Education.

Ellis, C., Adams, T.E., \& Bochner, A.P. (2011). Autoethnography: An overview. Historical Social Research, 36(4), 273-290.

Enns, C. \& Sinacore, A. (2005), Teaching and social justice: Integrating multicultural and feminist theories in the classroom. Washington, DC: American Psychological Association.

Fanon, F. (1968), The wretched of the Earth. New York: Grove.

Finger, M. \& Asun, J.M. (2001), Adult education at the crossroads: Learning our way out. London: Zed.

Gradstein, M., Justman, M., \& Meier, V. (2005), The political economy of education: Implications for growth and inequity. Cambridge, MA: MIT Press.

Gramsci, A. (1988), Gramsci's prison letters (Translated by Hamish Henderson). London: Zwan.

Granovetter, M.S. (1973), The strength of weak ties. The American Journal of 
Sociology, 78(6), 1360-1380.

Hobson, J.A. (1902), Imperialism: A case study. London: Nesbit \& Co.

Jarvis, P. (2008). The consumer society: Is there a place for traditional adult education? Convergence, XLI(1), 11-27.

Leverenz, C. (2000), Tenure and promotion in rhetoric and composition. College Composition and Communication, 52(1), 143-147.

Linvill, D. (2011), The relationship between student identity development and the perception of political bias in the college classroom. College Teaching, 59(2), 49-55.

Mannoni, O. (1950), Prospero and caliban. Paris: Le Seuil.

McLaren, P. (2005), Capitalists and conquerors: A critical pedagogy against empire. Oxford: Rowman \& Littlefield.

Memmi, A. (1965), The coloniser and the colonised. Boston: Beacon.

Plato (2000), The republic (Edited by G.R.F. Ferrari, translated by T. Griffith). Cambridge, U.K.: Cambridge University Press.

Rhoades, G., \& Slaughter, S. (1997). Academic capitalism, managed professionals, and supply-side higher education. Social Text, 51, 15(2), 9-38.

Rhoades, G., \& Slaughter, S. (2004). Academic capitalism in the new economy: Challenges and choices. American Academic, 1(1), 37-60.

Sabates, M. (2003), Being without doing. Topoi, 22, 111-125.

Slaughter, S. \& Rhoades, G. (2004). Academic capitalism and the new economy. Baltimore, MD: The John Hopkins University Press.

Snyder, T.D., \& Dillow, S.A. (2011), Digest of education statistics 2010. Washington, DC: U.S. Department of Education. NCES 2011-015. 
Usher, R. (2008). Consuming learning. Convergence, LXI(1), 29-45.

Youngman, F. (2000), The political economy of adult education \& development. London: Zed. 